\title{
DIFICULDADES DE APRENDIZAGEM: OS DESAFIOS DA CARREIRA DOCENTE
}

\author{
Fabiana Cabral da Silva ${ }^{1}$ Jerônimo Sartori ${ }^{2}$ \\ ${ }^{1}$ Especialista em Educação: Interdisciplinaridade e Transversalidade, Universidade Federal do Pampa, Unipampa. \\ fabyanacs@yahoo.com.br. \\ ${ }^{2}$ Professor da Universidade da Fronteira Sul. Professor do curso de Especialista em Educação: Interdisciplinaridade e \\ Transversalidade, Universidade Federal do Pampa. jetori55@yahoo.com.br.
}

\begin{abstract}
RESUMO
O presente artigo trata das dificuldades de aprendizagem apresentadas por educandos da educação básica, bem como tal fato tem se tornado cada vez mais um desafio à carreira docente. Trata-se de uma pesquisa qualitativa, envolvendo também pesquisa bibliográfica. $O$ trabalho teve como método, a aplicação de questionários para educadores da disciplina de Língua Portuguesa, que atuam em Escolas Públicas Estaduais de Ensino Fundamental e Médio do Município, município de São Gabriel, RS. Teve como objetivo principal, identificar as causas e as consequências que as "dificuldades de aprendizagem" trazem, tanto para educadores como para educandos, no que se refere ao desempenho no processo de ensino-aprendizagem. Também traz discussões acerca da interdisciplinaridade nas escolas, da formação de educadores, das metodologias utilizadas pelos mesmos durante suas práticas educativas, além de descrever e analisar de modo coerente os dados obtidos na investigação.
\end{abstract}

Palavras-chave: Ensino-aprendizagem. Interdisciplinaridade. Prática pedagógica. Professor. Alunos.

\section{ABSTRACT}

The present article deals with learning difficulties presented by Basic Education students and how this fact has become increasingly challenging for the teaching career. This study is qualitative also involving literature review. Questionnaires were applied to Portuguese teachers who work in the Basic Education Elementary and High School in public State schools in the city of São Gabriel, Rio Grande do Sul State. The aim of the article was to identify the causes and the consequences that the "learning difficulties" bring to both teachers and students in relation to their performance in the teaching-learning process. It also brings about the interdisciplinary discussion in schools, teacher training and the teaching methods used by them during their educational practices. In addition, it consistently describes and analyzes the data obtained in the investigation.

Keywords: Teaching-learning. Interdisciplinary. Pedagogical practice. Teacher. Students. 


\section{INTRODUÇÃO}

Ser educador não é e nunca foi tarefa fácil, são muitos os problemas, as dificuldades, as incertezas, as preocupações, enfrentadas por esses profissionais na trajetória de sua carreira docente. Dentre as dificuldades pode-se citar, por exemplo, a falta de motivação, o desinteresse dos educandos, as dificuldades de aprendizagem, além disso, existem também problemas relacionados às condições de trabalho, com as quais os profissionais da área da educação convivem diuturnamente. Além disso, pode-se citar também o descaso do próprio governo para com os profissionais da educação; salários defasados, plano de carreira que não atende as necessidades docentes, estes são alguns dos aspectos que confirmam o quão difícil é ser um educador, levando em conta também a política nacional de valorização do magistério no Brasil.

Considerando as dificuldades indicadas, o presente artigo trata, em especial, dos desafios que os educadores encontram em relação ao processo de ensino-aprendizagem, deixando de lado aspectos como as dificuldades encontradas no âmbito de infra-estrutura e da valorização salarial. Por meio deste estudo busca-se esclarecer as causas e as consequências relacionadas às dificuldades encontradas no processo de ensino-aprendizagem, do qual fazem parte os educadores e os educandos.

Este artigo apresenta em seu desenvolvimento alguns argumentos sobre "A interdisciplinaridade", como uma das maneiras que pode contribuir para a melhoria do processo ensino-aprendizagem. Traz um breve tópico relacionado à formação de educadores, o qual mostra que existem muitos pontos que ainda necessitam ser discutidos em relação ao tema em questão. Aponta, também, aspectos ligados às questões metodológicas, falando sobre o desenvolvimento da prática docente. Apresenta, ainda, uma descrição crítico-reflexiva detalhada acerca dos dados coletados por meio da aplicação do questionário; por fim traz algumas considerações finais, que trata dos resultados obtidos no estudo desenvolvido.

\section{METODOLOGIA}

Para realização do presente trabalho o primeiro passo dado foi a delimitação do tema que seria desenvolvido-trabalhado. Assim, devido a inúmeras dificuldades que se apresentam no cotidiano escolar e, sobretudo, no desenvolvimento de um trabalho docente de qualidade, ficou evidenciada a importância deste tema, bem como a necessidade de esclarecimentos, os quais só seriam possíveis, a partir de uma pesquisa.

Desse modo, dentre os vários fatores que contribuem para obstaculizar o trabalho docente, "a dificuldade de aprendizagem" por parte dos educandos, foi escolhida por tratar-se de um aspecto significativo, o qual tem sido motivo de constantes debates entre os docentes na atualidade, não só entre eles, mas também pela sociedade em geral.

Assim, "O objetivo maior de qualquer movimento intelectual é sempre atingir a ponta, isto é, chegar ao estágio da oferta de respostas a uma necessidade humana" (SANTOS, 1999, p. 26). Por isso, o mais importante nesta pesquisa, considera-se ser a qualidade dos dados obtidos como uma das formas de alcançar as respostas necessárias ao entendimento do porquê deste problema, ou seja, destas dificuldades. 
Após a escolha do referido tema, passou-se, então, à escolha da melhor forma de buscar esclarecer os porquês de tantas dificuldades, além disso, compreender quais fatores poderiam estar relacionados a este fato. Para tanto, a modalidade utilizada para que o presente trabalho pudesse ser desenvolvido, foi por meio da aplicação de um questionário, o qual tratou de questões relacionadas aos problemas de aprendizagem que ocorrem no dia-a-dia da vida escolar, bem como as dificuldades que os docentes encontram para que o ensino ocorra de forma a possibilitar a construção de conhecimentos, também, as alternativas que poderiam ser adotadas para que o ensino e a aprendizagem pudessem ser melhorados. Assim, a pesquisa de campo, foi desenvolvida com educadores que atuam no Ensino Fundamental e Médio, na área de Língua Portuguesa, em Escolas Públicas Estaduais do Município de São Gabriel, RS. Foi elaborado um questionário contendo dados de identificação, com exceção do nome do(a) pesquisado(a), isso como forma de deixá-lo(a) mais à vontade no momento de responder aos questionamentos. 0 instrumento foi elaborado contendo nove (9) questões dissertativas, as quais tratavam sobre: causas e consequências das dificuldades de aprendizagem, desenvolvimento de trabalhos interdisciplinares na escola, além, de faixa etária dos estudantes e classe social a qual pertenciam.

Os questionários foram deixados com os(as) supervisores(as) nas escolas e repassados aos educadores para serem respondidos. Também foi estabelecido um prazo para, posterior, recolhimento dos mesmos.

Outro ponto interessante e que fez parte do desenvolvimento deste estudo foi a pesquisa bibliográfica, a qual forneceu subsídios para uma detalhada compreensão acerca dos fatos que se buscava esclarecer com a pesquisa. A importância da pesquisa bibliográfica em trabalhos científicos pode ser confirmada, por meio do texto que segue: “Qualquer espécie de pesquisa, em qualquer área, supõe e exige pesquisa bibliográfica prévia, quer à maneira de atividade exploratória, quer para o estabelecimento do status quaestionis, quer para justificar os objetivos e contribuições da própria pesquisa" (RUIZ, 1992, p. 57).

\section{EDUCAÇÃO E INTERDISCIPLINARIDADE}

Para que haja uma educação de qualidade muitos aspectos precisam ser considerados. Mas, o que seria uma educação de qualidade? Ao falar sobre educação muitos são os conceitos que cercam esse tema. Para o momento trago a seguinte definição: "A educação é o processo pelo qual a sociedade forma seus membros à sua imagem e em função de seus interesses" (PINTO, 1993, p. 29). Tendo como base o conceito de educação, o homem é formado, considerando-se as necessidades de uma sociedade que está preocupada com o bem-estar de seus indivíduos, com o atendimento às suas demandas.

Na verdade, a escola está a serviço do Estado, do sistema dominante, pois, é ele quem dita regras e as diretrizes de organização e de funcionamento dos sistemas de ensino. Dessa forma, a educação ao atender os interesses da classe dominante, justifica porque ainda hoje ela se desenvolve de forma fragmentada, disciplinar, desarticulada e descontextualizada em relação à realidade social e ao mundo do trabalho.

Entende-se ser de grande importância para amenizar o que se denomina de "ensino fragmentado" o desenvolvimento de práticas pedagógicas interdisciplinares, que visem a totalidade do conhecimento. De acordo com Paviani:

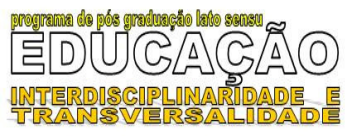


A época em que vivemos e as mudanças da sociedade brasileira precisam de uma visão mais abrangente e completa dos problemas e das alternativas de solução que a educação escolar exige. A visão interdisciplinar pode oferecer opções mais adequadas e eficazes (PAVIANI, 1986, p. 14).

Com certeza, a interdisciplinaridade é uma das formas que os educadores encontram para aperfeiçoar sua prática docente, possibilitando aos seus educandos um trabalho diferenciado, com melhores chances de ser desenvolvido com êxito, de cativar a atenção e o interesse dos educandos. De acordo com Ferreira (2009, p. 22): “[...] a interdisciplinaridade pode ser compreendida como sendo um ato de troca, de reciprocidade entre as disciplinas ou ciências - ou melhor, de áreas do conhecimento".

Por meio da prática interdisciplinar é possível relacionar diferentes áreas do conhecimento em torno de uma mesma temática, integrando conteúdos afins. Pela prática interdisciplinar é possível envolver vários educadores, os quais podem dialogar entre si, revendo conceitos acerca do tema trabalhado, isto é, planejando coletivamente e com determinação situações pedagógicas que visem a totalidade do conhecimento. Em conjunto, torna-se mais fácil organizar práticas interdisciplinares que atenda às necessidades de integração de saberes para determinado grupo de educandos, levando em conta a realidade dos sujeitos em situação de aprendizagem.

Dessa maneira, a prática docente exercida na perspectiva da interdisciplinaridade, tem boas possibilidades de atingir o seu objetivo maior que é a construção de conhecimentos significativos pelos alunos, pois: "A interdisciplinaridade do professor pode envolver e modificar o aluno quando ele assim o permitir" (TAVARES, 2009, p. 30). Outro ponto importante é que não basta o educador ser interdisciplinar, é fundamental, também, que o educando queira apreender aquilo que lhe está sendo apresentado de forma integrada.

A interdisciplinaridade favorece aos próprios educadores a se reeducarem no que diz respeito à maneira de problematizar e ver o mundo, de selecionar e organizar os conteúdos, os quais atualmente ainda são vistos de forma fragmentada. Conforme afirma Ferreira: "[...] ser interdisciplinar é saber que o universo é um todo, [...]" (2009, p. 20), por isso, deve-se agir, principalmente no que diz respeito à educação, pensando no todo e não apenas nas partes. Contudo, para que a interdisciplinaridade possa ocorrer é necessário que haja o engajamento de todo o corpo docente da escola, pois, para que o trabalho atinja os objetivos de integrar diferentes saberes é fundamental que todos desenvolvam suas práticas coletivamente, relacionando as diferentes áreas do conhecimento. Para isso, é muito importante que cada educador tenha algum conhecimento acerca dos conteúdos que não fazem parte da sua área específica de atuação, que estão envolvidos em outras áreas, as quais devem ser consideradas no decorrer do trabalho que se pretende como sendo interdisciplinar.

Por exemplo, a Língua Portuguesa, é fundamental na formação de cidadãos capazes; pode ser relacionada com diversas áreas como: Artes, Ciências, Matemática, Geografia, História, já que em cada uma delas é necessário que haja interpretação de textos, o que é importante para que os educandos possam desenvolver suas habilidades, não só em Português, mas em todas as demais áreas do conhecimento. No entanto, não é uma prática fácil de ser adotada, já que não depende somente de um único educador, mas do grupo, talvez, por isso, não aconteça nas escolas a 
interdisciplinaridade como uma prática comum, mas de essencial importância para o êxito do processo de ensino-aprendizagem.

Ainda existe um longo caminho a ser percorrido para que a interdisciplinaridade se torne realidade na prática pedagógica dos professores de educação básica, no cotidiano das escolas. Todavia, o importante é que cada educador que acredita nos benefícios que a prática interdisciplinar pode trazer para a educação, continue esforçando-se para que a interdisciplinaridade seja assumida como atitude entre os professores. De acordo com Fazenda (2009, p. 18): “O projeto interdisciplinar surge às vezes de um (aquele que já possuía em si a atitude interdisciplinar) e se contamina para os outros e para o grupo", daí a importância de cada um, mesmo que de forma isolada, comece a lutar por aquilo que acredita.

\section{FORMAÇÃO DE EDUCADORES: UM COMPROMISSO POLÍTICO-PEDAGÓGICO}

Um aspecto relevante em relação ao compromisso com os aspectos político e pedagógico na escola é, sem dúvida alguma, a questão da formação de educadores, considerada de fundamental importância ao processo de qualificação do ensino e da aprendizagem. Para que se possa exercer de maneira eficiente, seja qual for a profissão, o sujeito, antes de tudo, necessita ter uma formação que o qualifique para o desempenho de suas atividades.

A profissão docente, em especial, é bastante delicada no que se refere ao processo de formação, haja vista que os educadores lidam diretamente com pessoas; as pessoas querendo ou não, estão tendo seu caráter moldado a partir da escola, ou seja, de seus educadores. Assim sendo,

Nosso próprio agir como professores, as decisões tomadas diante de casos concretos, o funcionamento da escola como um todo, os procedimentos didáticos, têm eficácia na produção de comportamentos éticos. Entre mostrar e dizer como se deve proceder e o exemplo concreto do próprio agir não pode haver contradição sob pena de falsificar o que se pretende ensinar (PAVIANI, 1986, p. 110).

Com relação à formação universitária, os cursos de licenciatura, também precisam passar por algum aperfeiçoamento. É claro que o conhecimento científico que se adquire por meio das universidades é imprescindível para que haja uma formação de qualidade. Porém, o enfoque de muitas instituições de ensino superior tem sido voltado para a formação de profissionais que atendam as demandas de uma sociedade capitalista, de uma clientela elitista.

O que realmente deveria ser priorizado tem, na verdade, sido esquecido pela grande maioria dos cursos superiores - licenciaturas. Mas, isso não ocorre só nas universidades, já que a educação, como um todo, tem sido refém de imposições que procedem do sistema, ou seja, é o Estado quem decide o que e como fazer. As escolas acabam sendo apenas meios intermediários, os locais onde os educandos aprendem a ser aquilo que a sociedade deseja que eles sejam.

Cabe aos educadores, mas não somente a eles, o papel de começar a mudar a realidade educacional. De acordo com Kramer: "[...] uma proposta político-pedagógica precisa incluir um projeto político de sociedade e um conceito de cidadania, de educação e de cultura" (apud SARTORI; SEGAT, 2010, p. 123). Por isso, a importância do desenvolvimento de políticas que 
atendam realmente às necessidades da população, sem esquecer que cada povo, cada realidade possui a sua cultura, a sua organização social, política e econômica.

Todas estas questões precisam estar inclusas nos cursos de formação docente, para que o processo de ensino-aprendizagem possa ocorrer de forma significativa, pois, os educadores e os gestores educacionais necessitam considerar a condição sócio-cultural de cada comunidade, de cada educando. Isso pode ser confirmado por meio da afirmação: "A visão puramente escolar da educação só pode ser alienada e artificial, impossibilita a aprendizagem, pois o ato educativo e pedagógico é, ao mesmo tempo, um ato social, político, ético, religioso, científico [...]" (PAVIANI, 1986, p. 23).

Nas universidades, o estágio curricular, tem sido uma das maneiras de aperfeiçoar o processo de formação dos futuros educadores, já que é por meio dele que os futuros profissionais têm acesso à realidade que é vivenciada no dia a dia das escolas. No entanto, de acordo com Sartori e Segat, o estágio nas licenciaturas precisa de aperfeiçoamento, já que: "Um dos maiores desafios no processo de formação de professores consiste em repensar os moldes em que se realiza o estágio curricular" (2010, p. 112).

O maior problema se refere ao fato de que, muitas vezes, durante o período de estágio, o estagiário demonstra um grande comprometimento com a educação, o que não permanece após a conclusão da graduação. Daí a necessidade de criar, nos estagiários, futuros educadores, uma mentalidade voltada para o planejamento de suas ações, para a prática da reflexão acerca dos resultados da própria ação docente, devendo existir o replanejamento da prática quando as evidências do processo indicarem tal condição. Acredita-se que isso será possível através de reformulações curriculares que venham satisfazer as demandas de cada curso de licenciatura, além disso, também, por meio da prática da interdisciplinaridade por parte dos educadores recém formados, pois, com certeza, esta é uma alternativa capaz de interligar teoria e prática.

Outro ponto bastante importante e que merece atenção, no que se refere à formação dos profissionais da área da educação, é o fato de que eles precisam estar em constante busca pelo conhecimento, ou seja, precisam renovar sua pedagogia, seus métodos de ensino, suas práticas educativas. Isso é possível por meio de cursos, de pesquisas, de tudo o que possa, de uma maneira ou de outra, colaborar para com a formação continuada desses profissionais. A respeito disso, encontra-se apoio na seguinte passagem que diz: "A preparação do educador é permanente e não se confunde com a aquisição de um tesouro de conhecimentos que lhe cabe transmitir a seus discípulos" (PINTO, 1993, p. 48).

Tudo o que os cursos de formação de professores, de formação continuada oferecem, realmente são necessários para que esses profissionais possam atuar de forma a preparar os educandos para a vida em sociedade, para o exercício pleno de sua cidadania, para sua inserção no mundo do trabalho. Isso não pode realizar-se de forma alienada, mas de forma crítica e participativa, tendo plena consciência de que cada indivíduo é único, que todos somos seres "inacabados", nisso Freire corrobora ao enfatizar que: "Gosto de ser gente porque, inacabado, sei que sou um ser condicionado, mas consciente do inacabamento, sei que posso ir mais além dele" (1996, p. 53). 


\section{CAMINHOS DA PRÁTICA DOCENTE}

Ao falar em caminhos para o desenvolvimento da prática docente no decorrer do processo de ensino-aprendizagem, deve-se antes ter um entendimento, uma visão clara sobre os conceitos que envolvem as expressões: método e metodologia, já que ambas participam ativamente do desenvolvimento de práticas de ensino.

A palavra método é originária do Grego, tendo o seguinte significado: méthodos, de metá que significa pelo, através e hodós que significa caminho. Assim, "O método traz, dentro de si, a idéia de uma direção com a finalidade de alcançar um propósito, não se tratando, porém, de uma direção qualquer, mas daquela que leva, de forma mais segura, à consecução de um propósito buscado" (RAYS, 2000, p. 92-93).

Já a metodologia, neste caso, está diretamente ligada, ao processo de ensinoaprendizagem, pois, trata dos métodos de ensino, ou seja, dos caminhos, das estratégias (técnicas e recursos) utilizadas pelos educadores, algo que facilita a mediação entre o aluno e o objeto do conhecimento (os conteúdos), para que a aprendizagem dos estudantes seja realmente concretizada. Isso pode ser conferido na citação a seguir:

O método de ensino, desse modo, é condicionado e condicionador dos ambientes de aprendizagem. Nesse sentido, o método de ensino deve ser entendido como caminho através do qual se promova uma ação pedagógica consciente, organizada criticamente, com a finalidade de tornar o trabalho docente e discente mais fácil e mais produtivo para o alcance das metas desejadas e necessárias para o desenvolvimento integral dos educandos (RAYS, 2000, p. 92).

Atualmente, o que se percebe é que existe um consenso geral por parte dos professores, em relação à falta de interesse e motivação, por parte dos alunos. Isso foi verificado, também, por meio da pesquisa realizada com os docentes nas escolas, o que reforça a preocupação com esta situação. As perguntas que ficam são as seguintes: Por quê falta interesse ao aluno? Qual seria o motivo, ou os motivos, que têm levado à falta de interesse por parte dos estudantes? Será que os responsáveis são somente os estudantes ou será que os professores também têm sua parcela de responsabilidade em relação a esta situação?

É certo que se não houver um mínimo de interesse por parte dos educandos em apreender aquilo que lhes é ensinado pelos educadores o processo de ensino-aprendizagem não ocorre, pois: "Não há docência sem discência", conforme destaca Freire (1996). Um educando que não quer construir conhecimento é o mesmo que não ter este educando para ensinar, pois, não se pode forçar ninguém a fazer aquilo que não deseja.

Por outro lado, é importante salientar também, que os professores a partir de seus métodos de ensino, podem ou não criar condições de ensino-aprendizagem, levando à motivação ou não dos alunos. É de fundamental importância que os docentes ao exercer sua prática pedagógica tenham em mente a consciência de refletir sobre suas próprias práticas. A despeito disso, Freire enfatiza que: "Por isso é que, na formação permanente dos professores, o momento 
fundamental é o da reflexão crítica sobre a prática. É pensando criticamente a prática de hoje ou de ontem que se pode melhorar a próxima prática" (1996, p. 39).

Muitas são as metodologias que podem ser utilizadas pelos educadores durante o processo de ensino-aprendizagem. Na Língua Portuguesa, por exemplo, podem ser trabalhados textos, charges, fábulas, vídeos, confecção de cartazes, uso de data-show, entre outros recursos didáticos. Contudo, é necessário que se leve em conta sempre as reais condições materiais das unidades escolares, nas quais o trabalho docente é realizado.

A prática da interdisciplinaridade, como já citado anteriormente, é essencial como forma de aperfeiçoar a ação docente de forma integrada e vinculada às problemáticas do contexto em que se insere a comunidade escolar. Como já está explicito neste texto as ações interdisciplinares favorecem a interconexão entre as diferentes disciplinas do currículo escolar. Da mesma forma, ao trabalhar com relatórios, resumos em disciplinas como Ciências, por exemplo, o professor pode corrigir os erros de Português cometidos pelos estudantes na elaboração das atividades indicadas, contribuindo para com o aprendizado dos mesmos em todas as disciplinas do currículo da educação básica. São coisas simples, mas que na prática podem surtir grandes efeitos no que se refere à aprendizagem significativa.

Um fator que, com certeza, interfere na aprendizagem, bem como no interesse dos alunos em aprender refere-se a memorização dos conteúdos. Muitas são as situações em que o docente avalia o educando apenas por aquilo que ele foi capaz de memorizar a partir do conteúdo trabalhado, não pelo que compreendeu, nem pelas relações que consegue realizar ou deixa de estabelecer. Não existe incentivo para os educandos buscarem respostas para as questões que tenham sido levantadas pelo professor em sala de aula. Ou para aquelas que tenham sido levantadas pelos próprios estudantes no decorrer do processo de ensino-aprendizagem. Então,

É exatamente neste sentido que ensinar não se esgota no "tratamento" do objeto ou do conteúdo, superficialmente feito, mas se alonga à produção das condições em que aprender criticamente é possível. E essas condições implicam ou exigem a presença de educadores e de educandos criadores, instigadores, inquietos, rigorosamente curiosos, humildes e persistentes (FREIRE, 1996, p. 26).

Nesse sentido, não é tarefa somente do professor ser crítico, instigador, curioso, essa natureza é essencial também ao agir do educando. Todavia, embora isso se constitua em algo relevante, não tem sido tratado com a devida reflexão, pois, é o uso do livro didático que guia e orienta a maior parte da ação dos docentes, praticamente, é a única forma metodológica de ensino. Muitos educadores são totalmente contra a utilização deste recurso didático, por entenderem que enquanto houver o uso exclusivo do livro didático a educação terá dificuldades para avançar, ou seja, o ensino continuará na base da transmissão-memorização-reprodução.

É preciso destacar, porém, que o problema pode, na realidade, não estar no uso do livro didático, mas na forma como este instrumento e/ou recurso didático de trabalho é utilizado pelos prossores no cotidiano das escolas de educação básica. Na verdade,

[...] os materiais de apoio ao trabalho na sala de aula são muito necessários, e cabe ao professor selecionar o melhor material disponível diante da sua própria realidade. Sua 
utilização deve ser feita de maneira que possa constituir um apoio efetivo, oferecendo informações corretas, apresentadas de forma adequada à realidade de seus alunos (BIZZO, 2009, p. 83-84).

Para que o processo ensino-aprendizagem seja possível, existem dois pontos essenciais, que sem eles não há ensino e muito menos aprendizagem. Em primeiro lugar está a questão da ética profissional, que "a partir de pressupostos éticos gerais e básicos, tenta legitimar princípios morais aceitos em determinada comunidade como sendo de validade comum" (PAVIANI, 1986, p. 104). Querendo ou não, os educadores servem de exemplo para os educandos, daí a necessidade de ter conduta ética diante das várias e difíceis situações que se apresentam no decorrer da trajetória docente, pois, "Sua ação como educador expressa uma escolha que influencia o comportamento do estudante" (PAVIANI, 1986, p. 105), ou seja, o comportamento dos professores pode ter influência positiva ou negativa para o processo formativo dos alunos.

Em segundo lugar, está a questão da competência profissional; por mais que um educador seja "bom" para os educandos, mas se ele não apresentar competência no desenvolvimento do trabalho docente, não terá como criar condições que possibilitem aos alunos a construção de novos conhecimentos, isto é, não haverá, neste caso, nem ensino e nem aprendizagem. De acordo com as palavras de Freire:

A segurança com que a autoridade docente se move implica uma outra, a que se funda na sua competência profissional. Nenhuma autoridade docente se exerce ausente desta competência. O professor que não leve a sério sua formação, que não estude, que não se esforce para estar à altura de sua tarefa não tem força moral para coordenar as atividades de sua classe. [...] O que quero dizer é que a incompetência profissional desqualifica a autoridade do professor (1996, p. 91-92).

Desse modo, os caminhos da prática docente são os meios, pelos quais, ainda é possível a criação de condições para que o processo ensino-aprendizagem obtenha êxito, tornando o estudante sujeito e agente de seu próprio processo de produção-construção de conhecimento.

\section{DESCRIÇÃO DOS DADOS COLETADOS}

Neste tópico do artigo estão descritos, os dados desta pesquisa, os quais foram obtidos por meio da aplicação de um questionário para educadores da disciplina de Língua Portuguesa que atuam no Ensino Fundamental e Médio em escolas de educação básica de São Gabriel - RS. Esta descrição tem como base a realização de um olhar crítico-reflexivo acerca dos registros formulados por meio das respostas ao instrumento.

Dos questionários enviados retornaram oito, os quais são objeto de análise neste estudo. Percebeu-se pelas respostas ao instrumento que duas das professoras atuam, não somente na disciplina de Língua Portuguesa, mas, também, na disciplina de Literatura Brasileira, não ministram aulas no Ensino Fundamental, desenvolvendo sua docência apenas no Ensino Médio. Provavelmente, o fato destas duas professoras desenvolverem seu trabalho apenas no Ensino Médio, esteja relacionado ao fato delas trabalharem com a disciplina de Literatura Brasileira, 
sendo que esta não se encontra na grade curricular do Ensino Fundamental, somente do Ensino Médio. Uma destas professoras atua em turmas de 1ㅇ, 2ㅇ e $3 \circ$ anos, enquanto que a outra atua apenas em turmas de 1 o ano deste nível de ensino.

Todos os pesquisados que responderam ao questionário são do sexo feminino, sendo que uma delas não respondeu onde atua, dizendo apenas que atua no Ensino Fundamental e Médio, não indicando série(s) ou ano(s). A maioria das respondentes atua no Ensino Fundamental e Médio simultaneamente, principalmente, em turmas de 7ạ e 8a séries do Ensino Fundamental e em turmas de 10 , 2ㅇ e 3응 anos do Ensino Médio.

Em relação à idade as educadoras as mesmas estão na faixa etária entre os 26 aos 45 anos, sendo que uma das respondentes não forneceu este dado. Todos os itens analisados até o momento referem-se aos dados de identificação das pesquisadas, os quais foram solicitados por intermédio do questionário aplicado.

A análise que segue diz respeito aos educandos, às práticas educativas desenvolvidas pelas educadoras, aos problemas encontrados na ação docente, bem como às possibilidades pedagógicas que poderiam ser adotadas para auxiliar no processo de ensino-aprendizagem. Por meio dos questionamentos realizados, foi abordada, também, a questão da prática da interdisciplinaridade como meio de contribuição para melhoria deste processo educativo. Inicialmente, o relato acerca da idade dos educandos revela que eles estão entre 10 e 19 anos. A pesquisa realizou-se com professores de Ensino Fundamental e Médio, por isso, é que os níveis de idade apresentam tais diferenças no que tange à faixa etária.

O que se percebeu, é que existem educandos, que se encontram adiantados, já que estão na 5a série com apenas 10 anos de idade, outros já se encontram atrasados na relação idade-série, pois, geralmente a idade de término do Ensino Médio fica em torno dos 17 anos. Já no Ensino Fundamental, levando em conta aqueles educandos que entraram no período certo e não reprovaram, estes por sua vez terminam tal nível de ensino com idade entre 14 e 15 anos.

Sobre a aprendizagem dos estudantes, os docentes ao serem questionados sobre quais seriam os problemas enfrentados por eles acerca do aprendizado, indicam a falta de interesse e de motivação por parte dos mesmos; item este que apareceu recorrentemente como resposta. Além disso, a falta de entusiasmo, de disciplina, de hábitos de estudo em casa; a leitura consiste noutro ponto abordado pelas professoras. Apenas uma delas mencionou o fato de os familiares não estarem presentes na escola, já outra pesquisada falou sobre o excesso de conteúdo gramatical nas grades curriculares, indicando, ainda como entrave a limitada a carga horária para o entendimento e o bom desempenho do educando. Um aspecto relacionado exclusivamente ao ensino da Língua Portuguesa refere-se à questão dos educandos não saberem realizar interpretação de texto, fato que segundo as pesquisadas está relacionado à falta do hábito de leitura.

Entende-se que tudo o que fora mencionado pelas educadoras faz parte da realidade vivida no ambiente escolar. A partir deste estudo pode-se, não só constatar, mas, também, confirmar o quanto é difícil desenvolver um trabalho de qualidade diante de tantas dificuldades encontradas; o que pode ser ainda pior pela falta do apoio necessário para que esta realidade possa ser modificada.

Também, foi apontado pelas respostas que o distanciamento da família, o não acompanhamento do desempenho dos filhos na escola, dificulta o estabelecimento de limites para

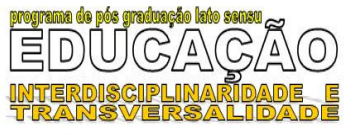


o bom andamento das aulas. Fora relatado sobre a falta de conscientização por parte dos alunos, no que tange à importância do saber, do conhecimento, do convívio em sociedade, além disso, falta maturidade, há ausência de metas, de sonhos a serem alcançados para a vida futura. Como conseqüência, apontou-se principalmente o déficit no rendimento escolar, o que causa elevados índices de repetência. De certo modo, tais indicativos condizem com a baixa qualidade da educação, tendo como consequência, jovens cada vez mais despreparados para a vida, para o mundo do trabalho, para viver e conviver em sociedade. Devido a isso, os docentes e o próprio sistema de ensino, não conseguem alcançar as expectativas esperadas em relação à educação, tais aspectos também desmotivam os próprios professores e gestores educacionais.

Com certeza, são inúmeros os motivos que fazem aumentar a preocupação entre os docentes com a educação escolar, principalmente por parte daqueles que realmente se preocupam e se comprometem com a questão. Diante de tantos desafios, cabe a cada educador, buscar soluções que possam pelo menos, minimizar este quadro de desolação, de desencanto, pelo qual passa a educação brasileira atualmente.

Também foi perguntado às educadoras sobre a condição social dos educandos, bem como se isso, de alguma forma, pode ou não afetar o processo ensino-aprendizagem. A maioria das respostas foi de que "não". A visão é de que a falta de condições não atrapalha no processo de aprendizagem, segundo a educadora $5^{3}$ : "Não afeta em nada, pois uma coisa é a pessoa ter vontade de vencer e lutar, a escola é pública e a falta de condições não interfere em nada".

Mas, uma educadora manifestou-se em sentido contrário, dizendo que sim, que a condição social quando precária poderá afetar a aprendizagem dos educandos. Segundo a educadora 6: "Sim, pois as diferenças sociais transparecem no aprendizado em razão de os pais dos alunos de classe menos favorecidas terem menos instrução". Talvez em razão disso, não possam auxiliar e/ou orientar seus filhos nos estudos, na execução das tarefas escolares indicadas.

Na verdade, em se tratando de condição social baixa, de alguma forma, mesmo que não seja no rendimento escolar, mas, por exemplo, na auto-estima do educando, ela poderá interferir. É claro que existem aqueles que exatamente por ter uma condição social desfavorável, lutam por melhores condições, neste caso, sua condição social poderá não interferir em seus estudos. Porém, há aqueles, que por se sentirem inferiores aos demais poderão ter seu rendimento escolar afetado. Desse modo, fica difícil generalizar a interferência do aspecto social no desempenho do educando. Depende do ponto de vista de cada professor, de como cada um lida com esta problemática no cotidiano da sala de aula, com o modo de ser de cada educando.

As alternativas pedagógicas adotadas pelas professoras para que o ensino de Língua Portuguesa se torne mais atrativo aos estudantes, consiste basicamente na diversificação das atividades, considerando-se os recursos didáticos existentes na escola. Nesse sentido, vários recursos foram citados pelas pesquisadas para tornar as aulas na disciplina de Língua Portuguesa mais atrativas aos alunos, tais como: filmes, músicas, revistas, jornais, teatro, sala de leitura, atividades virtuais, envolvendo jogos educativos e testagem de conhecimentos. Além disso, duas professoras mencionaram também, o fato de estabelecer relação entre os conteúdos com a realidade dos estudantes. A educadora 5 ressalta que: "Alternativas até existem, mas o maior problema é o público que na verdade não quer trabalhar e executar as atividades propostas". Neste

\footnotetext{
${ }^{3}$ Os recortes dos depoimentos das professoras serão indicados por um número arábico, número atribuído conforme a ordem de retorno dos questionários respondidos. 
quesito fica evidente a falta de interesse e de motivação em realizar as atividades indicadas pelas educadoras.

De acordo com a maioria das pesquisadas são várias as alternativas pedagógicas existentes, que podem contribuir para a melhoria do processo ensino-aprendizagem. Pode-se perceber, também, que todas as alternativas são relativamente fáceis de serem adotas no cotidiano escolar. Porém, ficam as perguntas: Será que essas alternativas têm sido testadas na prática pelas professoras? Todas as professoras pesquisadas acreditam naquilo que escreveram? Tais questionamentos só poderiam ser respondidos se fosse observado o exercício docente em cada situação no cotidiano da escola.

Sobre o tema interdisciplinaridade no ambiente escolar, primeiramente foi perguntado se o educador realiza algum tipo de trabalho interdisciplinar em suas práticas de sala de aula, bem como o que cada um realiza e que resultados esta prática traz para a aprendizagem do educando. Como resultado obteve-se três respostas negativas, afirmando não desenvolver nenhum tipo de trabalho interdisciplinar em suas aulas, já cinco das respostas dadas foram afirmativas, expressam que desenvolvem trabalhos interdisciplinares durante as práticas pedagógicas.

No entanto, das cinco respostas afirmativas apenas duas parecem compreender o sentido de um trabalho interdisciplinar, pois, falam sobre a interação entre as diversas disciplinas, também sobre o desenvolvimento de projetos que criam nos alunos habilidades que podem ser trabalhadas de forma integrada entre as diversas áreas do conhecimento.

Ainda, três das respostas afirmativas demonstraram que as educadoras pensam estar realizando a interdisciplinaridade apenas por utilizarem textos que tratem de assuntos diversos. Um ponto positivo no que foi dito é que estes textos trazem temas que estão envolvidos em outras áreas do conhecimento, mas na verdade são trabalhados apenas no horizonte da língua. Pode até não ser uma prática de interdisciplinaridade, no sentido real da palavra, mas, com certeza, representa um passo que estas professoras estão dando rumo ao aprimoramento de sua prática docente.

Referente à interdisciplinaridade abordou-se que há muitas dificuldades para desenvolver um trabalho integrado na perspectiva de uma prática interdisciplinar. As respostas foram praticamente unânimes, afirmando que: "há falta de tempo para o planejamento conjunto das atividades" entre os educadores das diferentes disciplinas na escola. Apenas a educadora 3 mencionou faltar: "A conscientização por parte dos professores em relação ao trabalho em conjunto, uma equipe que troca ideias e experiências, trabalhando com o todo e não com uma parte fragmentada. É preciso estar aberto às mudanças tão necessárias para o entrosamento entre professores e alunos".

Não se pode julgar quando o professor diz não ter tempo para reunir-se com os demais colegas para desenvolvimento de determinado projeto na escola. Isso porque a realidade vivida por grande parte dos educadores é a de trabalhar sessenta (60) horas semanais, como forma de manter um padrão de vida adequado às suas exigências, ou para solucionar o problema da escola por falta de professores.

No que tange ao questionamento sobre com quais áreas a disciplina de Língua Portuguesa seria facilmente relacionável. Novamente as respostas foram quase unânimes entre as pesquisadas, enfatizando que toda a disciplina é passível de se relacionar com as demais áreas do conhecimento. Em se tratando de Língua Portuguesa isso se torna ainda mais explicito, já que esta é uma disciplina que serve como base para todas as outras do currículo escolar.

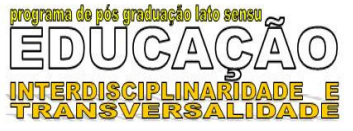


No que se refere à opinião das pesquisadas sobre a importância da interdisciplinaridade na escola. As respondentes concordam que a prática da interdisciplinaridade constitui uma maneira de contribuir para a melhoria do processo de ensino-aprendizagem, porém, algumas opiniões se referem ao fato de que não é fácil de ser trabalhada de forma satisfatória, mais uma vez aparece a questão da falta de tempo para o planejamento e o desenvolvimento de práticas interdisciplinares, de maneira eficiente e eficaz.

Acerca disso a educadora 1 expressa que a interdisciplinaridade: "É válida se fluir naturalmente de acordo com a situação de aprendizagem e os interesses discentes do momento. Não é eficiente se imposta e, com prazo marcado para efetivar-se". Na verdade é uma conclusão importante e oportuna, já que qualquer projeto que se desenvolva de forma imposta não tem as mesmas chances de sucesso do que aquele que se desenvolve de forma natural, ou seja, que emerge de uma problemática ou de uma necessidade do grupo. E mais ainda,

No projeto interdisciplinar não se ensina, nem se aprende: vive-se, exerce-se. A responsabilidade individual é a marca do projeto interdisciplinar, mas essa responsabilidade está imbuída do envolvimento - envolvimento esse que diz respeito ao projeto em si, às pessoas e às instituições a ele pertencentes (FAZENDA, 2009, p. 17, grifo do autor).

Nesse sentido, não basta que o projeto seja bom, o mais importante é na realidade, que haja o comprometimento de cada docente, dedicando-se ao planejamento e à realização da ação proposta. Como disseram as pesquisadas é ótima a ideia de desenvolver o processo ensinoaprendizagem de forma interdisciplinar, mas é preciso que haja participação, compromisso, envolvimento efetivo de todos aqueles que fazem parte do grupo de educadores em cada unidade escolar.

\section{CONSIDERAÇÕES FINAIS}

A pesquisa realizada, da qual trata o presente artigo, considerou o aspecto qualitativo e não o aspecto quantitativo dos dados obtidos. Deste modo, buscou-se, em primeiro lugar considerar a qualidade das informações, sendo que a quantidade de dados obtidos não influenciaria nos resultados desta análise descritivo-crítica.

A referida pesquisa originou-se das indagações sobre as dificuldades encontradas pelos educadores durante o desenvolvimento de suas práticas pedagógicas, no decorrer da carreira docente. A partir de então, o foco ficou centralizado na questão das dificuldades de aprendizagem apresentadas pelos educandos conforme a visão das professoras pesquisadas, o que se constituiu num dos grandes desafios para a educação no momento contemporâneo.

Como instrumento de coleta de dados, utilizou-se a aplicação de um questionário. A aplicação do instrumento foi realizada diretamente com as professoras como forma de obter as informações necessárias ao desenvolvimento do projeto. Um dos maiores problemas encontrados ao aplicar questionário, é o fato de que o retorno dos mesmos nem sempre ocorre conforme se espera, mas este é um dos riscos que se corre ao adotar este tipo de instrumento para a coleta de dados, especialmente quando o questionário é formulado com questões abertas. 
No total foram deixados dezesseis (16) questionários em Escolas Públicas Estaduais, onde atuam professores no Ensino Fundamental e no Ensino Médio, no município de São Gabriel - RS, o questionário foi composto por nove (9) questões a serem respondidas de forma dissertativa, além dos dados de identificação dos pesquisados.

Os instrumentos deveriam ser respondidos pelos educadores de Língua Portuguesa. Dos dezesseis (16) questionários enviados apenas oito (8) retornaram, ou seja, $50 \%$ do total, embora tenha sido estabelecido um prazo para a devolução dos mesmos. 0 acerto da devolução dos questionários foi realizado com as coordenadoras pedagógicas das escolas, não diretamente com os professores, mesmo assim o percentual de devolução destes instrumentos ficou aquém do esperado.

Os resultados obtidos nesta pesquisa permitem expressar que, segundo as pesquisadas os baixos índices de aprendizagem que se têm atualmente, devem-se principalmente, ao desinteresse e à falta de motivação por parte dos estudantes. Este dado tem sido o motivo apontado não somente pelas professoras pesquisadas, mas pela grande maioria das falas informais que se realiza com os docentes que atuam em escolas de educação básica.

De acordo com esta realidade muitas podem ser as causas da "dita" falta de interesse e desmotivação. Entre elas pode-se destacar que muitos educandos vão à escola, não porque querem adquirir conhecimento, mas em razão da Bolsa Família ${ }^{4}$, já que muitas vezes as famílias são de baixa renda e precisam desta ajuda do governo para se manter. Embora este item não tenha sido apontado como causa pelas pesquisadas, com certeza, influencia na decisão de estar na escola ou não, de ter interesse ou não na aprendizagem.

Já ao falar em falta de apoio familiar, o que se percebe é que os pais pouco se interessam pela vida escolar dos filhos, sem dúvida, isto de alguma forma torna mais difícil o processo de aprendizagem; o educador tem maiores dificuldades de estabelecer um contrato didático e exigir mais empenho do educando. Porém, esta falta de apoio familiar nem sempre está relacionada ao fato de os pais não terem interesse pelos filhos, muitas vezes, estes pais não possuem conhecimentos suficientes para auxiliar os filhos no que diz respeito aos seus estudos, à realização das tarefas propostas pelos professores.

Outra questão que também não foi levantada pelas educadoras, mas que certamente tem influência direta no processo de ensino-aprendizagem é o modo como os professores têm desenvolvido o seu trabalho, ou seja, as estratégias didáticas apresentadas pelos mesmos para que a aprendizagem se torne interessante e efetiva. Essas causas, com certeza, podem servir como objeto de estudo, para futuras investigações.

Acredita-se que a responsabilidade pelas dificuldades de aprendizagem apresentadas pelos educandos, não esteja apenas na falta de apoio familiar e nem no desinteresse destes. Ao contrário, há também uma grande responsabilidade por parte dos docentes, já que são estes que organizam as situações de ensino para desenvolver em sala de aula com os educandos. A forma como os conhecimentos estão sendo levados é que entra em questão, ou seja, as metodologias utilizadas em sala de aula. Será que as mesmas estão sendo desenvolvidas de maneira a criar condições de aprendizagem para os educandos? E, além disso, será que despertam o interesse dos

\footnotetext{
${ }^{4}$ Bolsa Família Programa do Governo Federal de transferência direta de renda com condicionalidades, que beneficia famílias em condições de pobreza e extrema pobreza. Fonte: www.mds.gov.br/bolsafamilia. 
educandos pelos conteúdos apresentados em sala de aula? Estas são questões que deveriam ser analisadas criticamente por cada docente, em seu cotidiano escolar.

Outro fato de suma importância é a questão de que nem sempre o professor possui o hábito de reflexão sobre suas práticas pedagógicas; atitude considerada adequada ao (re)planejamento da ação docente. O que se percebe, no dia a dia da escola, é que na maioria das vezes, não há uma preocupação com o planejamento, com a elaboração dos planos de ensino, com o encadeamento vertical e horizontal dos conhecimentos curriculares. Estas são práticas que jamais deveriam ser deixadas de lado pelos educadores, isto porque são formas de aperfeiçoar o desenvolvimento das próprias práticas pedagógicas.

Por exemplo, um método que tenha sido utilizado e que por algum motivo não alcançou o objetivo esperado, poderá ser repensado, melhorando, para o próximo planejamento. O repensar as metodologias, bem como o desenvolvimento da prática docente, certamente, poderá contribuir para que o ensino e a aprendizagem sejam significativos e, além disso, poderá despertar um maior interesse dos educandos em aprender.

Fora apontado pelas professoras as dificuldades de interpretação de texto por parte dos alunos. Este é um dado preocupante, já que no $\mathrm{ENEM}^{5}$, bem como na maioria das provas de vestibulares ainda existentes, que são as portas de entrada para as universidades, as questões são na sua essência interpretativas. Com a evidência de tal lacuna, como esses educandos poderão ingressar na universidade? O certo é que, este ingresso só será possível se os educandos tiverem a habilidade de interpretação exigida pelas questões propostas nas provas seletivas para o ingresso na educação superior.

No que tange à interdisciplinaridade, constatou-se ser este um dos meios, através do qual o processo de ensino-aprendizagem poderá ser qualificado e desenvolvido na perspectiva da totalidade do conhecimento. Todas as professoras pesquisadas concordaram com a crescente necessidade que se tem de integrar o conhecimento e que o mesmo não pode continuar sendo ministrado de forma fragmentada em partes isoladas, como acontece no cotidiano das escolas nos dias atuais.

A principal dificuldade apontada refere-se à falta de tempo dos educadores para organizar e, posteriormente colocar em prática um projeto interdisciplinar. Mas, como julgá-los com referência a isso, pois, sabe-se o quanto é restrito o tempo que os educadores têm para reuniões e estudos em conjunto. Há dificuldades até para preparar os planos de ensino para que não haja sobreposição de conteúdos entre áreas afins, quanto mais para o planejamento, execução e avaliação de projetos de natureza interdisciplinar.

Fica como importante a consideração que necessita ser dispensada pelos educadores acerca da importância da realização de trabalhos coletivos no cotidiano da escola. A partir do momento em que ficar clara esta necessidade, o avanço da educação poderá dar sinais de concretude, pois, aqueles que desempenham suas atividades com compromisso ético, político, social, dedicação e amor, com certeza, otimizarão seu tempo em favor da qualificação do processo de ensino-aprendizagem para favorecer a emancipação do educando.

\footnotetext{
${ }^{5}$ ENEM - Exame Nacional do Ensino Médio realizado, anualmente, pelo Governo Federal. Atualmente é utilizado como critério classificatório para o ProUni (Programa Universidade para Todos), que distribui bolsas, totais ou parciais, em faculdades e universidades particulares, para alunos de baixa renda. A nota do ENEM também é utilizada como critério de seleção de alunos por várias faculdades e universidades, públicas e particulares. Fonte: www.cursoenem.org.br/O-QUE-E-O-ENEM.asp.

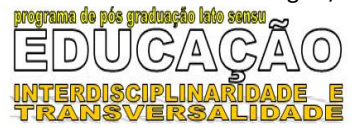




\section{REFERÊNCIAS}

BIZZO, Nelio. Ciências: fácil ou difícil? São Paulo: Biruta, 2009.

FAZENDA, Ivani. Interdisciplinaridade: definição, projeto, pesquisa. In: FAZENDA, Ivani (Org.). Práticas interdisciplinares na escola. 11. ed. São Paulo: Cortez, 2009.

FERREIRA, Maria Elisa de M. P. Ciência e interdisciplinaridade. In: FAZENDA, Ivani (Org.). Práticas interdisciplinares na escola. 11. ed. São Paulo: Cortez, 2009.

FREIRE, Paulo. Pedagogia da autonomia: saberes necessários à prática educativa. 39. ed. São Paulo: Paz e Terra, 1996.

PAVIANI, Jaime. Problemas de Filosofia da Educação. 3. ed. Caxias do Sul, EDUCS, 1986.

PINTO, Álvaro Vieira. Sete lições sobre educação de adultos. 8. ed. São Paulo: Cortez, 1993.

RAYS, Oswaldo Alonso. Metodologia do ensino: cultura do caminho contextualizado. In:

(org.). Educação e Ensino: constatações, inquietações e proposições. Santa Maria: Pallotti, 2000. p. 89-102.

RUIZ, João Álvaro. Metodologia científica. 3. ed. São Paulo: Atlas, 1992. p. 57-63.

SANTOS, Antonio Raimundo dos. Tipos de pesquisa. In: SANTOS, Antonio Raimundo dos. Metodologia científica: a construção do conhecimento. Rio de Janeiro: DPeA, 1999.

SARTORI, Jerônimo; SEGAT, Taciana Camera. Educação freireana: a formação docente como ato de libertação. In: ANDREOLA, Balduino Antonio et al (orgs.). Formação e educação: da itinerância das universidades à escola itinerante. Ijuí: Editora Unijuí, 2010. p. 111-128.

TAVARES, Dirce Encarnación. Aspectos da história deste livro. In: FAZENDA, Ivani (org.). Práticas interdisciplinares na escola. 11. ed. São Paulo: Cortez, 2009. 